\title{
Comparison of psychological impact of COVID-19 pandemic on Health Care Professionals working in COVID versus Non COVID health care facilities in India: a cross-sectional study
}

\author{
Savita Chahal ${ }^{1}$, Prashant Srivastava ${ }^{2}$, Anuradha $\mathrm{Nadda}^{3}$, Nikhil Govil ${ }^{4}$, Priyanka Dang ${ }^{5}$, \\ Nishu Gupta ${ }^{6}$, Zahid Ali Khan ${ }^{7}$, Abhinav Dagar ${ }^{8}$
}

${ }^{1}$ Associate Professor, Department of Psychiatry, Kalpana Chawla Government Medical College (KCGMC), Karnal, Haryana.

${ }^{2}$ Psychiatric Social Worker, Department of Psychiatry, Kalpana Chawla Government Medical College (KCGMC), Karnal, Haryana.

${ }^{3}$ Assistant Professor, Department of Community Medicine, Dr. B.R. Ambedkar State Institute of Medical Science, Mohali, Punjab.

${ }^{4}$ Associate Professor, Department of General Medicine, Kalpana Chawla Government Medical College (KCGMC), Karnal, Haryana.

${ }^{5}$ Clinical Psychologist, Department of Psychiatry, Kalpana Chawla Government Medical College

(KCGMC), Karnal, Haryana.

${ }^{6}$ Department of Pediatrics, PGIMER Satellite Centre, Sangrur, Punjab.

${ }^{7}$ Assistant Professor, Department of Community Medicine, Government Medical College Baramulla.

${ }^{8}$ Assistant Professor, Department of Pulmonary Medicine, Kalpana Chawla Government Medical College (KCGMC), Karnal, Haryana.

Corresponding author: Anuradha Nadda

Email - dranuradhapgims@gmail.com

\section{ABSTRACT}

Background: The study aimed to compare the psychological impact of COVID-19 pandemic on health care professionals (HCPs).

Methodology: It was a cross sectional study carried out on health care professionals (doctors, nursing staff and paramedical HCPs) in India. Depression, generalized anxiety, panic symptoms, hypochondriacal and obsessional symptoms were assessed through questions based on ICD-10 criteria. A pre tested google questionnaire was prepared and its link was sent through various social media.

Results: A total of $626 \mathrm{HCPs}$ ( 385 doctors, 124 nursing staff, 117 Paramedical HCPs) were included in the study. Depression, generalized anxiety, panic symptoms, hypochondriacal symptoms and obsessional symptoms were found in $13.3 \%, 21.2 \% 5.1 \%, 16.5 \%$ and $32.6 \%$ of the HCPs respectively. Depression, generalized anxiety and panic symptoms were found to be significantly higher in the HCPs of COVID health care facilities ( $\mathrm{p} 0.009 ; \mathrm{p}<0.001 ; \mathrm{p} 0.035$ respectively). Female HCP was associated with depression [OR 2.34 (1.38-3.96); p-0.002] and panic symptoms [OR 3.43 (1.46-8.07); p-0.005]. Generalized anxiety was more common in HCPs working in COVID health care facilities [1.91 (1.20-3.03); $\mathrm{p}-0.006]$.

Conclusion: The study concludes that being a female health care professional, doctors and those working in COVID health care facilities were at a higher risk of having poor psychological health.

Keywords: psychological impact, depression, anxiety, physicians, COVID-19, mental health

(Paper received $-5^{\text {th }}$ July 2021, Peer review completed $-15^{\text {th }}$ August 2021)

(Accepted $-28^{\text {th }}$ August 2021, Published $-5^{\text {th }}$ January 2022)

\section{INTRODUCTION}

The Coronavirus disease 2019 (COVID-19) pandemic has emerged as the scariest of all health crises of 21st century. The first case of this disease occurred on December 8, 2019 in the Hubei province of China [1]. Since then, within a short span of just over 3 months, the infection has spread to 177 countries across the 
world, and on 11th March 2020 the World Health Organization declared it the global pandemic [2]. According to World Health Organization (2020) globally, as of 9 December 2020 (4:22pm CET), there have been 67,780,361 confirmed cases, 1,551,214 deaths of COVID-19 [3]. By 10th December; as on 08:00 IST 9,767, 371 cases have been reported in India due to COVID-19 [4] which are further expected to soar over next few months with increased testing and loosening of lockdown restrictions.

Such pandemics are highly likely to be associated with significant psychological and social impacts on healthcare workers as some previous international studies on COVID-19 suggest [5-7]. High risk of contracting COVID 19 compared to general population, difficulty balancing family and professional life, separation from homes due to professional demands, guilt of compromising on family front by the nature of job, huge amount of work, exhaustive duty hours, moral dilemma and wrath of patients' relatives make health care professionals more vulnerable to adverse mental health outcomes particularly for frontliners [89]. These factors are likely to adversely affect the psychological health of health care professionals which can manifest in the form of psychological distress, depressive or anxiety symptoms. The poor psychological health can weaken the self-confidence of health care professionals and is likely to adversely affect the health care delivery system precisely when it is most needed to function above par [8]. Therefore, this study is an attempt to gain insights into the better understanding of psychological impact of COVID-19 on various health care professionals in terms of quantification of magnitude and delineation of characteristics of depressive and anxiety symptoms as well as analysis of potential risk factors associated with them so that appropriate guidelines for psychological interventions targeting this vulnerable group may be planned and initiated timely.

\section{METHODOLOGY}

\section{Study design}

It was a cross sectional study carried out on health care professionals in India. An informed written consent was taken from the participants before the study after assuring them of the confidentiality of information and anonymous nature of survey.

\section{Sample size and sampling}

The sample size for this study was calculated by using the formula $\mathrm{N}=\mathrm{Z} \alpha 2 \mathrm{X} \mathrm{P}(1-\mathrm{P}) / 12$, in which $\alpha=$ $0.05, \mathrm{Z} \alpha=1.96$, and the acceptable margin of error for proportion (d) was 0.05 . In a study conducted by Lai et al the proportion of frontline health care professionals exposed to corona virus disease were estimated to have depression in $50.2 \%$ [5]. As study has considered subgroup analyses, the sample size was amplified by $50 \%$ with a goal of minimum 576 participants. A snowball sampling technique with convenience sampling was used for the purpose of this research.

\section{Methods}

The study duration was 29th March to 31st May 2020 inclusive of the period of pilot testing. The health care professionals (HCPs) who included doctors, nursing staff and paramedical heath care professionals like pharmacists, technicians, psychosocial professionals, occupational therapists and physiotherapists constituted the study population. Only those aged more than 18 years, working in allopathic system of medicine, able to understand English, with access to the internet and willing to give informed consent were included in the study. Those with history of pre-existing psychiatric illness, administrative staff and sanitation workers working in health care setting were excluded from the study. A pilot tested, semistructured, online questionnaire (kappa-0.8) comprising of four sections was designed by the investigators using google forms with consent form affixed to it. Section A of the questionnaire had questions pertaining to socio-demographic details (age, gender, marital status, religion, type of family and having dependent children), Section B focused on professional and personal characteristics such as type of health care professional, rank, speciality, nature of duties, workplace setting, comorbid medical or psychiatric illness, substance abuse), and Section C assessed about impact on psychological health. Psychological impact was determined in terms of depression, generalized anxiety, panic symptoms, hypochondriacal and obsessional symptoms and was assessed through questions based on ICD-10 criteria [10]. Depression was measured by 
1. low mood, 2. anhedonia 3. easy fatiguability as major criteria whereas 1 . poor concentration or attention 2. insomnia 3. change in appetite 4. ideas of unworthiness or hopelessness 5 . death wishes 6 . suicidal ideation 7. crying spells and 8. irritability were taken as minor criteria. Presence of at least two major and two minor criteria were considered as qualifiers for depression in our study.

Symptoms of anxiety were measured in following categories: i) Generalized anxiety: a. Apprehension (worries, nervousness, feeling on edge, everything getting on top) b. Motor tension (constant strain in head, inability to relax) c) autonomic overactivity (palpitation, chest pain, sweating, shortness of breath, dryness of mouth, trembling, nausea, light headedness). Generalized anxiety was considered to be present when symptoms from at least two out of these three domains (a to c) were reported. ii) Panic symptoms were said to be present when autonomic symptoms like palpitation, chest pain, sweating, shortness of breath, dryness of mouth, trembling, nausea, light headedness were severe enough to give a feeling of losing control, going mad or impending death due to COVID-19. iii) Hypochondriacal preoccupation was assessed by question: persistent preoccupation with the thought that one has already got COVID. iv) Obsessional symptoms were assessed by questions: repetitive, excessive and unreasonable thoughts of getting COVID and repetitively thinking about COVID when one did not mean to.

All symptoms were measured on four levels of scales 1) not at all 2) not more than usual 3) rather more than usual 4) much more than usual. Response of 1 and 2 were considered normal and 3 and 4 were considered as symptoms of psychological distress. All these symptoms were required to be present only after lockdown (i.e. 25th March 2020 onwards) [11]. A pilot study was initially conducted on 20 heath care professionals from 29th march to 10th April to validate the questionnaire and they were excluded from the final analysis. The link of this questionnaire as google form was sent from 16th April; through e- mails, WhatsApp and other social media to the friends, colleagues and other acquaintances of the investigators along with the request to forward the link further to as many health care professionals as possible within India; without any geographical restrictions. The participants got auto directed to the brief introduction and purpose of research and informed consent as they clicked the link. Those who consented to participate filled up the set of several questions that appeared subsequently. The study participants were divided into two groups based on whether they worked in a government designated COVID health care facility or Non-COVID health institute.

\section{STATISTICAL ANALYSIS}

Data was entered into Microsoft excel 2007 and analysis was performed using SPSS statistical software version 20.0 (IBM Corp., Armonk, NY, USA). The p value (significance level) was taken as $\leq 0.05$. Descriptive statistics were applied; independent $t$ test was used to calculate mean and standard deviations. Pearson's Chi-square test, Fisher exact test (wherever applicable) and binary logistic regression were used to determine potential risk factors for depression, generalized anxiety, panic symptoms, hypochondriacal and obsessional symptoms. Gender, marital status, family composition, type of type of health care professionals and health care facility, workplace setting were identified as confounders or covariates. Multiple bar charts were prepared by using Microsoft excel 2007.

\section{RESULTS}

\section{Distribution \& Demographics of the participants}

A total of 639 health care professionals responded to the survey conducted. Health Care Professionals from all states and union territories across India barring three states and four union territories participated in the study. As per selection criteria 626 participants were included in the final analysis out of which $344(55 \%)$ worked in a COVID Health care facility (Figure-1).

There was almost equal representation of both genders; overall and among doctors. Majority of the respondents among nursing staff (94.4) were females while it was otherwise among paramedical health care professionals where males (72.6\%) showed a preponderance Majority of the participants $(87.6 \%)$ were in the age group of $18-40$ years with 31-40 years emerging as the single largest group (36.4\%). Around $70 \%$ of the participants hailed from nuclear families. Close to half participants (42.5\%) were single. A large number 
of respondents (64.5\%) worked in Government sector. A total of 102 participants (16.3\%) were directly engaged in management of confirmed COVID cases (Table 1).

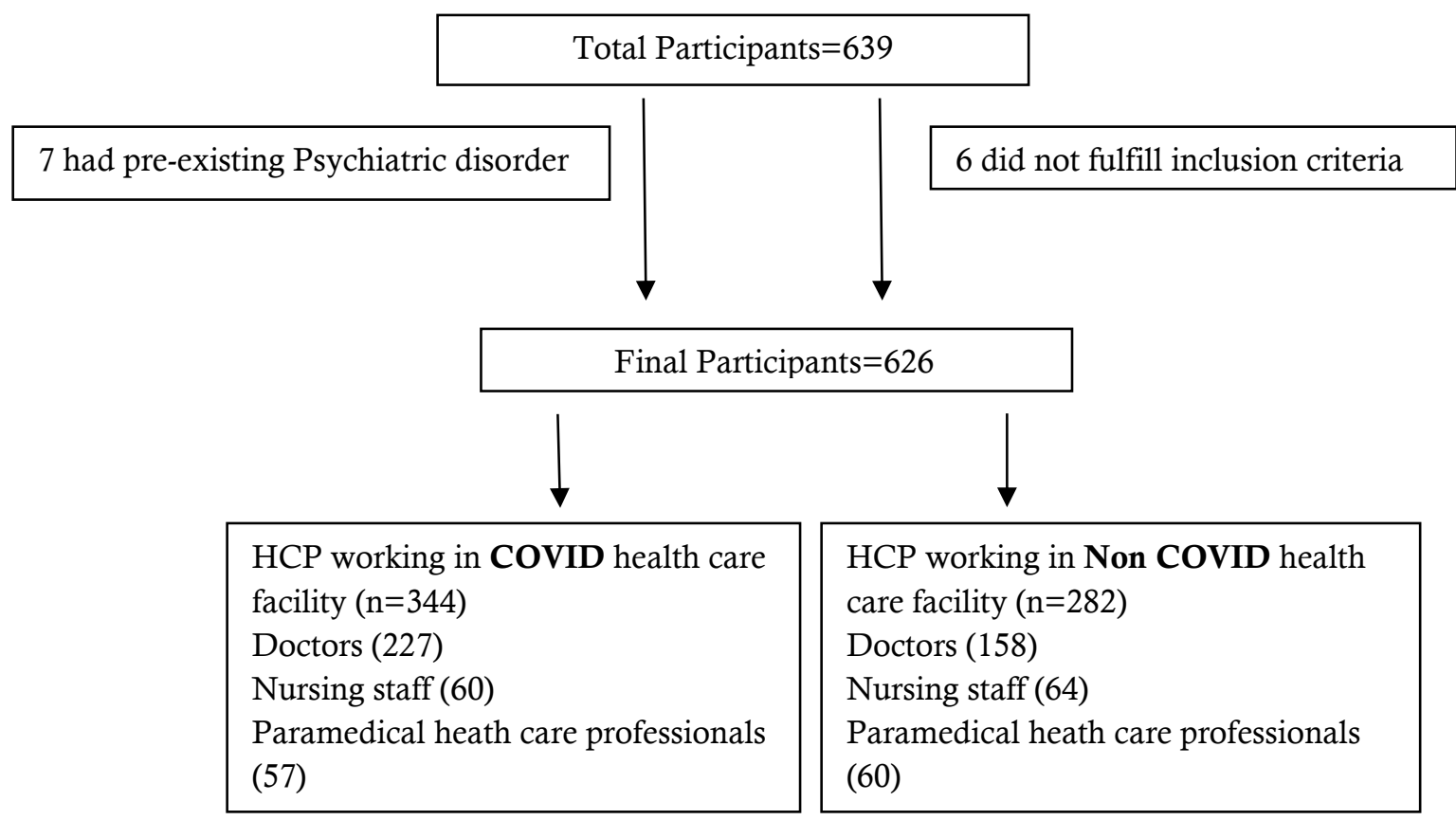

Figure1: Flow Diagram of the study participants

Table 1: Socio-demographic characteristics of study participants $(n=626)$

\begin{tabular}{|c|c|c|c|c|}
\hline Characteristics & $\begin{array}{c}\text { Doctors } \\
n=385\end{array}$ & $\begin{array}{c}\text { Nursing staff } \\
\mathrm{n}=124\end{array}$ & $\begin{array}{c}\text { Paramedical heath care } \\
\text { professionals } \\
n=117\end{array}$ & $\begin{array}{c}\text { Total } \\
n=626\end{array}$ \\
\hline \multicolumn{5}{|c|}{ Gender } \\
\hline Male & $208(54.0)$ & $07(5.6)$ & $85(72.6)$ & $300(47.9)$ \\
\hline Female & $177(46.0)$ & $117(94.4)$ & $32(27.4)$ & $326(52.1)$ \\
\hline \multicolumn{5}{|c|}{ Age Group } \\
\hline $18-25$ years & $82(21.3)$ & $50(40.3)$ & $15(12.8)$ & $147(25.3)$ \\
\hline $25-30$ years & $109(28.3)$ & $37(29.8)$ & $16(13.7)$ & $162(25.9)$ \\
\hline $31-40$ years & $152(39.5)$ & $28(22.6)$ & $48(41.0)$ & $228(36.4)$ \\
\hline$>40$ years & $42(10.9)$ & $09(7.3)$ & $38(32.5)$ & $89(14.2)$ \\
\hline \multicolumn{5}{|c|}{ Mean age (SD) } \\
\hline Male & $33.5(7.6)$ & $27.9(5.6)$ & $38.9(9.1)$ & $34.9(8.4)$ \\
\hline Female & $30.7(6.3)$ & $29.2(7.6)$ & $32.5(18.9)$ & $30.3(7.1)$ \\
\hline \multicolumn{5}{|c|}{ Religion } \\
\hline Hindu & $351(91.2)$ & $71(57.3)$ & $109(93.2)$ & $531(84.8)$ \\
\hline Muslim & $11(2.9)$ & $01(0.8)$ & $03(2.6)$ & $15(2.4)$ \\
\hline Sikh & $16(4.2)$ & $11(8.9)$ & $03(2.6)$ & $30(4.8)$ \\
\hline Christian & $03(0.8)$ & $39(31.5)$ & $01(0.9)$ & $43(6.9)$ \\
\hline Others & $04(1.0)$ & $02(1.6)$ & $01(0.9)$ & $07(1.1)$ \\
\hline \multicolumn{5}{|c|}{ Family Composition } \\
\hline Nuclear & $281(73.0)$ & $86(69.4)$ & $67(57.3)$ & $434(69.3)$ \\
\hline Joint & $104(27.0)$ & $38(30.6)$ & $50(42.7)$ & $192(30.7)$ \\
\hline
\end{tabular}




\begin{tabular}{|c|c|c|c|c|}
\hline \multicolumn{6}{|c|}{ Marital Status } \\
\hline Single & $159(41.3)$ & $80(64.5)$ & $27(23.1)$ & $266(42.5)$ \\
\hline Married & $226(58.7)$ & $44(35.5)$ & $90(76.9)$ & $360(57.5)$ \\
\hline \multicolumn{7}{|c|}{ Whether had dependent children } \\
\hline$\leq 2$ years & $43(11.2)$ & $09(7.3)$ & $05(4.3)$ & $57(9.1)$ \\
\hline 2-5 years & $64(16.6)$ & $12(9.7)$ & $18(15.4)$ & $94(15.0)$ \\
\hline$>$ 5 years & $52(13.5)$ & $16(12.9)$ & $55(47.0)$ & $123(19.6)$ \\
\hline No child & $226(58.7)$ & $87(70.2)$ & $39(33.3)$ & $352(56.2)$ \\
\hline \multicolumn{7}{|c|}{ Workplace Setting } \\
\hline Government & $265(68.8)$ & $50(40.3)$ & $89(76.1)$ & $404(64.5)$ \\
\hline Private & $120(31.2)$ & $74(59.7)$ & $28(23.9)$ & $222(35.5)$ \\
\hline \multicolumn{7}{|c|}{ Physical comorbidity } \\
\hline Yes & $64(16.6)$ & $16(12.9)$ & $17(14.5)$ & $57(15.5)$ \\
\hline No & $321(83.4)$ & $108(87.1)$ & $100(85.5)$ \\
\hline Yes & $72(18.7)$ & $12(9.7)$ & $18(15.4)$ & $102(16.3)$ \\
\hline No & $313(81.3)$ & $112(90.3)$ & $99(84.6)$ & $524(83.7)$ \\
\hline
\end{tabular}

Depression as a syndrome was estimated to be present in $13.3 \%$ of the health care professionals. Generalized anxiety was found in $21.2 \%$ of the HCPs. Panic symptoms, hypochondriacal preoccupation and obsessional symptoms were found in $5.1 \%, 16.5 \%$ and $32.6 \%$ of the study participants respectively. Depression, generalized anxiety and panic symptoms were found to be significantly higher in the health care professionals of COVID health care facilities ( $\mathrm{p}=0.009 ;<0.001 ; 0.035$ respectively) (Table-2).

Table 2: Comparison of psychological impact of COVID-19 on HCPs in COVID versus Non COVID Health care facilities $(n=626)^{*}$

\begin{tabular}{|c|c|c|c|c|}
\hline $\begin{array}{c}\text { Psychological Health } \\
\text { determinants }\end{array}$ & $\begin{array}{c}\text { COVID health care } \\
\text { facility } \\
\mathbf{( n = 3 4 4 )}\end{array}$ & $\begin{array}{c}\text { Non COVID } \\
\text { health care facility } \\
\mathbf{( n = 2 8 2 )}\end{array}$ & $\begin{array}{c}\text { Total } \\
\mathbf{( n = 6 2 6 )}\end{array}$ & $\mathbf{p}$ value \\
\hline Depression & $56(16.3)$ & $27(9.6)$ & $83(13.3)$ & $\mathbf{0 . 0 0 9}$ \\
\hline Generalized anxiety & $93(27.0)$ & $40(11.3)$ & $133(21.2)$ & $<\mathbf{0 . 0 0 1}$ \\
\hline Panic Symptoms & $23(6.7)$ & $09(3.2)$ & $32(5.1)$ & $\mathbf{0 . 0 3 5}$ \\
\hline $\begin{array}{c}\text { Hypochondriacal } \\
\text { preoccupation }\end{array}$ & $62(18.0)$ & $41(14.5)$ & $103(16.5)$ & 0.144 \\
\hline Obsessional symptoms & $120(34.9)$ & $84(29.8)$ & $204(32.6)$ & 0.102 \\
\hline
\end{tabular}

*value in parenthesis indicates percentage

Proportions of the mental health problems in HCP's

Depression $(p<0.001)$, generalized anxiety $(p<0.001)$, hypochondriacal preoccupation $(p<0.001)$ and obsessional symptoms $(<0.001)$ were found to be significantly higher among doctors compared to other health care professionals (Table 3 )

Female health care professionals had significantly higher prevalence of depression and panic symptoms compared to their male counterparts $(p=0.002 \& p=0.006)$. Marital status did not seem to have any significant influence on psychological health of health care professionals. Depression was significantly more common in HCPs who hailed from nuclear families $(p=0.035)$ Panic symptoms and generalized anxiety were significantly higher among government sector health care professionals $((p=0.029 \& 0.002$ respectively) (Table-4). 
Table 3: Comparison of psychological impact of COVID-19 on different groups of Health Care Professionals $(n=626)^{*}$

\begin{tabular}{|c|c|c|c|c|}
\hline $\begin{array}{c}\text { Psychological Health } \\
\text { determinants }\end{array}$ & $\begin{array}{c}\text { Doctors } \\
\mathbf{n = 3 8 5}\end{array}$ & $\begin{array}{c}\text { Nursing Staff } \\
\mathbf{n = 1 2 4}\end{array}$ & $\begin{array}{c}\text { Paramedical Health } \\
\text { care professionals } \\
\mathbf{n = 1 1 7}\end{array}$ & p value \\
\hline Depression & $68(17.7)$ & $12(9.7)$ & $3(2.6)$ & $<\mathbf{0 . 0 0 1}$ \\
\hline Generalized anxiety & $106(27.5)$ & $12(9.7)$ & $15(12.8)$ & $<\mathbf{0 . 0 0 1}$ \\
\hline Panic Symptoms & $24(6.2)$ & $5(4.0)$ & $3(2.6)$ & 0.239 \\
\hline $\begin{array}{c}\text { Hypochondriacal } \\
\text { preoccupation }\end{array}$ & $82(21.3)$ & $11(8.9)$ & $10(8.5)$ & $<\mathbf{0 . 0 0 1}$ \\
\hline Obsessional symptoms & $147(38.2)$ & $35(28.2)$ & $22(18.8)$ & $<\mathbf{0 . 0 0 1}$ \\
\hline \multicolumn{4}{|c|}{$\begin{array}{c}{ }^{*} \text { value in parenthesis indicates percentage } \\
\text { Comparison of mental health problems (subgroup analysis) }\end{array}$} \\
\hline
\end{tabular}

Table 4: Sociodemographic correlates of psychological impact of COVID-19 pandemic on health care professionals (n-626)*

\begin{tabular}{|c|c|c|c|c|c|}
\hline $\begin{array}{c}\text { Socio- } \\
\text { demographic } \\
\text { Characteristics }\end{array}$ & $\begin{array}{c}\text { Depression } \\
\text { n (\%) }\end{array}$ & $\begin{array}{c}\text { Generalized } \\
\text { anxiety } \\
\mathbf{n} \text { (\%) }\end{array}$ & $\begin{array}{c}\text { Panic } \\
\text { Symptoms } \\
\text { n (\%) }\end{array}$ & $\begin{array}{c}\text { Hypochondriacal } \\
\text { preoccupation } \\
\text { n (\%) }\end{array}$ & $\begin{array}{c}\text { OCD } \\
\text { symptoms } \\
\text { n (\%) }\end{array}$ \\
\hline \multicolumn{7}{|c|}{ Gender } \\
\hline Male & $27(9.0)$ & $54(18.0)$ & $08(2.7)$ & $48(16.0)$ & $89(29.7)$ \\
\hline Female & $56(17.2)$ & $79(24.2)$ & $24(7.4)$ & $55(16.9)$ & $115(35.3)$ \\
\hline p value & $\mathbf{0 . 0 0 2}$ & 0.035 & $\mathbf{0 . 0 0 6}$ & 0.427 & 0.079 \\
\hline \multicolumn{7}{|c|}{ Marital Status } \\
\hline Single & $33(12.4)$ & $52(19.5)$ & $13(4.9)$ & $47(17.7)$ & $87(32.7)$ \\
\hline Married & $50(13.9)$ & $81(22.5)$ & $19(5.3)$ & $56(15.6)$ & $117(32.5)$ \\
\hline p value & 0.338 & 0.214 & 0.489 & 0.275 & 0.512 \\
\hline \multicolumn{7}{|c|}{ Family Composition } \\
\hline Nuclear & $65(15.0)$ & $100(23.0)$ & $22(5.1)$ & $72(16.6)$ & $146(33.6)$ \\
\hline Joint & $18(9.4)$ & $33(17.2)$ & $10(5.2)$ & $31(16.1)$ & $58(30.2)$ \\
\hline p value & $\mathbf{0 . 0 3 5}$ & 0.060 & 0.540 & 0.496 & 0.226 \\
\hline \multicolumn{7}{|c|}{ Workplace setting } \\
\hline Government & $54(13.4)$ & $100(24.8)$ & $26(6.4)$ & $63(15.6)$ & $141(34.9)$ \\
\hline Private & $29(13.1)$ & $33(14.9)$ & $06(2.7)$ & $40(18.0)$ & $63(28.4)$ \\
\hline p value & 0.510 & $\mathbf{0 . 0 0 2}$ & $\mathbf{0 . 0 2 9}$ & 0.250 & 0.057 \\
\hline
\end{tabular}

Table 5: Risk factors for psychological distress identified by Binary Logistic Regression Analysis

\begin{tabular}{|c|c|c|c|}
\hline Variables & Adjusted OR (95\%CI) & p value (Category) & p value (Overall) \\
\hline \multicolumn{4}{|c|}{ Depression } \\
\hline \multicolumn{4}{|c|}{ Gender } \\
\hline Male & $1[$ Reference] & NA & NA \\
\hline Female & $2.34(1.38-3.96)$ & $\mathbf{0 . 0 0 2}$ & NA \\
\hline \multicolumn{4}{|c|}{ Family Composition } \\
\hline Joint & $1[$ Reference] & NA & \\
\hline & $1.48(0.84-2.62)$ & 0.175 & \\
& & & \\
\end{tabular}




\begin{tabular}{|c|c|c|c|}
\hline \multicolumn{4}{|c|}{ Type of health care professionals } \\
\hline $\begin{array}{l}\text { Paramedical heath care } \\
\text { professionals }\end{array}$ & 1 [Reference] & NA & $<0.001$ \\
\hline Doctors & $6.46(1.972-21.13)$ & 0.002 & \\
\hline Nursing staff & $2.35(0.62-8.86)$ & 0.207 & \\
\hline \multicolumn{4}{|c|}{ Type of institute } \\
\hline Non-COVID health care facility & 1 [Reference] & NA & NA \\
\hline COVID health care facility & $1.62(0.98-2.68)$ & 0.061 & \\
\hline \multicolumn{4}{|c|}{ Generalized Anxiety } \\
\hline \multicolumn{4}{|c|}{ Type of health care professionals } \\
\hline $\begin{array}{c}\text { Paramedical heath care } \\
\text { professionals }\end{array}$ & 1 [Reference] & NA & \multirow[t]{3}{*}{$<0.001$} \\
\hline Doctors & $2.50(1.38-4.53)$ & 0.002 & \\
\hline Nursing staff & $0.79(0.34-1.80)$ & 0.568 & \\
\hline \multicolumn{4}{|c|}{ Type of institute } \\
\hline Non-COVID health care facility & 1 [Reference] & NA & NA \\
\hline COVID health care facility & $1.91(1.20-3.03)$ & 0.006 & \\
\hline \multicolumn{4}{|c|}{ Workplace setting } \\
\hline Private & 1 [Reference] & NA & NA \\
\hline Government & $1.25(0.76-2.07)$ & 0.373 & \\
\hline \multicolumn{4}{|c|}{ Panic Symptoms } \\
\hline \multicolumn{4}{|c|}{ Gender } \\
\hline Male & 1 [Reference] & NA & NA \\
\hline Female & $3.43(1.46-8.07)$ & 0.005 & \\
\hline \multicolumn{4}{|c|}{ Type of health care professionals } \\
\hline $\begin{array}{c}\text { Paramedical Heath care } \\
\text { professionals }\end{array}$ & 1 [Reference] & NA & 0.264 \\
\hline Doctors & $2.02(0.59-7.01)$ & 0.266 & \\
\hline Nursing Staff & $1.02(0.22-4.70)$ & 0.985 & \\
\hline \multicolumn{4}{|c|}{ Type of institute } \\
\hline Non-COVID health care facility & 1 [Reference] & NA & NA \\
\hline COVID health care facility & $1.47(0.62-3.50)$ & 0.38 & \\
\hline \multicolumn{4}{|c|}{ Workplace setting } \\
\hline Government & 1 [Reference] & NA & NA \\
\hline Private & $2.23(0.82-6.12)$ & 0.118 & \\
\hline \multicolumn{4}{|c|}{ Obsessional Symptoms } \\
\hline \multicolumn{4}{|c|}{ Type of health care professionals } \\
\hline $\begin{array}{l}\text { Paramedical heath care } \\
\text { professionals }\end{array}$ & 1 [Reference] & NA & $<0.001$ \\
\hline Doctors & $2.67(1.61-4.43)$ & $<0.001$ & \\
\hline Nursing staff & $1.70(0.93-3.12)$ & 0.087 & \\
\hline \multicolumn{4}{|c|}{ Hypochondriacal preoccupation } \\
\hline \multicolumn{4}{|c|}{ Type of health care professionals } \\
\hline $\begin{array}{c}\text { Paramedical heath care } \\
\text { professionals }\end{array}$ & 1 [Reference] & NA & \multirow[t]{3}{*}{$<0.001$} \\
\hline Doctors & $2.90(1.45-5.79)$ & 0.003 & \\
\hline Nursing staff & $1.04(0.43-2.55)$ & 0.929 & \\
\hline
\end{tabular}

Effects of confounders on mental health problems

Analysis of binary logistic regression showed being female HCP was associated with depression [OR 2.34 (1.38-3.96); $\mathrm{p}-0.002$ ] and panic symptoms [OR 3.43 (1.46-8.07); $\mathrm{p}-0.005$ ]. Compared to paramedical heath 
care professionals, doctors were associated with depression [OR 6.46(1.972-21.13); p-0.002], anxiety [OR 2.50 (1.38-4.53); p-0.002], obsessional symptoms [OR 2.67 (1.61-4.43); $\mathrm{p}-<0.001$ ] and hypochondriacal preoccupation [OR 2.90 (1.45-5.79); p- 0.003]. Generalized anxiety was more common in HCPs working in COVID health care facilities [OR 1.91 (1.20-3.03); p-0.006] (Table-5).

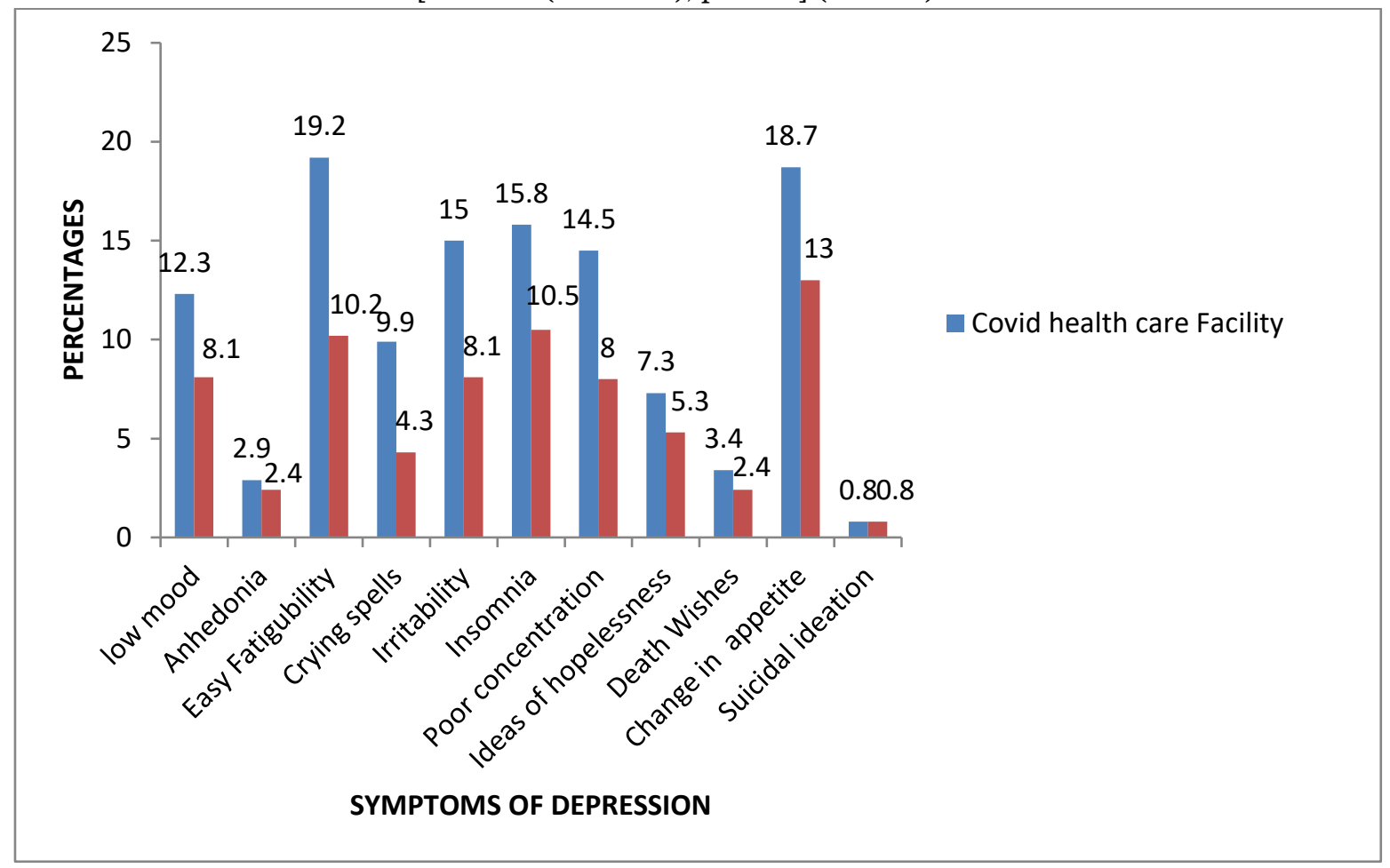

Figure 2: Comparison of depressive symptoms in health care professionals of COVID versus Non COVID health care facilities $(n=626)$

\section{Symptoms of depression and anxiety}

Change in appetite (31.7\%) followed by easy fatiguability (29.4\%) and insomnia (26.3) emerged as the most common symptoms of depression. Easy fatiguability $(p=0.001)$, crying spells $(p=0.002)$, irritability ( $p$ 0.004 ), and poor concentration ( $\mathrm{p}-0.006$ ) were significantly more common among health care professionals of COVID health care facilities compared to those working in Non COVID health care facilities (Figure-2).

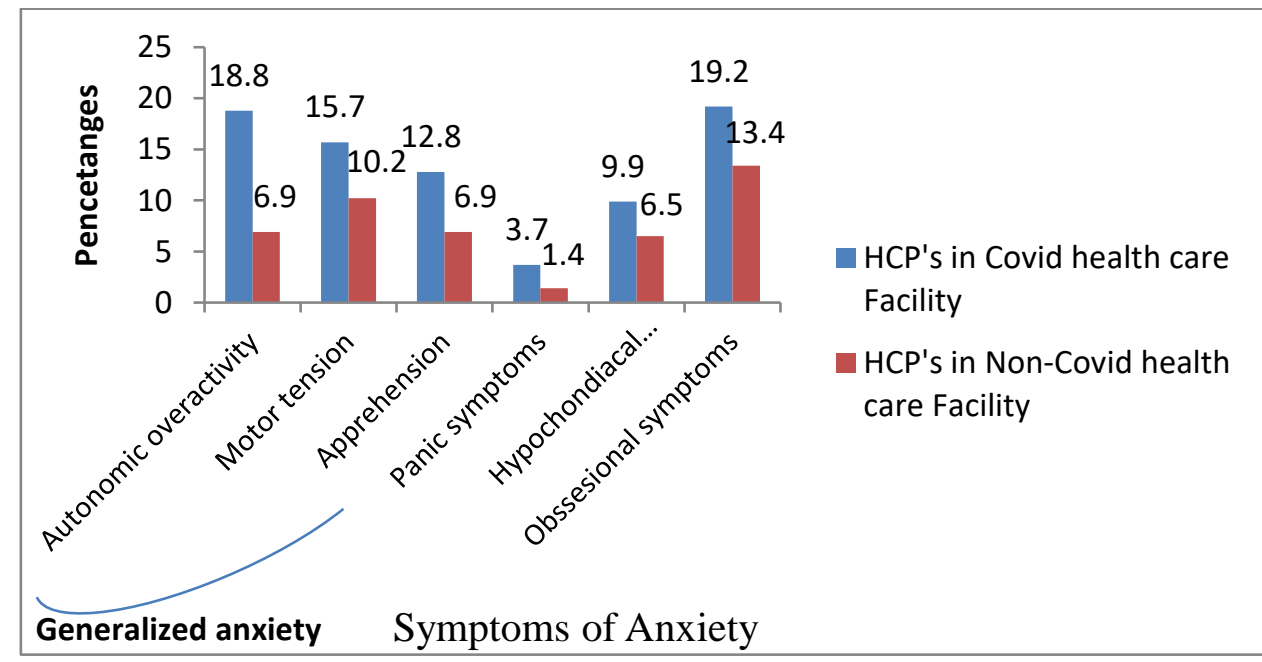

Figure 3: Comparison of anxiety symptoms between health care professionals of COVID versus Non COVID health care facilities $(n=626)$ 
Obsessional symptoms (32.6\%) were the most common among all anxiety spectrum symptoms. Symptoms of all anxiety spectrum disorders viz. generalized anxiety, panic symptoms, hypochondriacal and obsessionals symptoms were more common among health care professionals of COVID health care facilities compared to their Non COVID counterparts (Figure 3).

\section{DISCUSSION}

The present study is among the first few Indian studies to investigate the psychological effects of the recent outbreak of coronavirus disease 2019 (COVID-19) on healthcare professionals across India. This crosssectional study recorded a total of 626 responses from doctors, nursing staff and paramedical health care professionals. Majority of the respondents were doctors, were married and worked in designated COVID health care facilities though a large number of them $(84.6 \%)$ were not involved in direct dealing of confirmed COVID cases. A study from India is showing that health care providers are in psychological distress and suffering adverse social impact due to COVID-19 pandemic [12].

The overall prevalence of depression, generalized anxiety, panic symptoms, hypochondriacal and obsessional symptoms among study participants was $13.3 \%, 21.2 \%, 5.1 \%$ and 16.5 and $32.6 \% \%$ respectively which is comparable to a similar study from Singapore by Tan et al. in which $14.5 \%$ participants screened positive for anxiety, $8.9 \%$ for depression, $6.6 \%$ for stress, and $7.7 \%$ for clinical concern of PTSD [7]. However, in another study from China, a considerably higher proportion of participants had experienced symptoms of depression (50.4\%), anxiety (44.6\%) and insomnia (34.0\%) [5]. This contrast might be explained by the use of different study tools and also the fact that the impact of COVID-19 pandemic in India was not as severe as that in China at the time of study and preventive measures in India were being implemented and health care professionals were better informed about these measures than those in countries affected earlier by the pandemic.

The results of the study also showed that the severity of various mental health problems among doctors, nursing staff and paramedical health care professionals was relatively differential. The study findings imply that the prevalence of various psychiatric morbidities (depression, anxiety, panic, hypochondriacal and obsessional symptoms) regardless of whether one worked in COVID or Non COVID health care facility, was more among doctors compared to that among nursing staff and paramedical healthcare professionals. Our findings further indicate that depression and panic symptoms were more commonly reported among female health care professionals compared to their male counterparts. These findings are in line with the results of another study from China in which females reported more severe symptom levels of anxiety, depression and insomnia than men (severe anxiety among men vs women:3.4\% vs $5.8 \%$; $=0.001$ ) However in contrast to our study they found nurses to be more commonly affected by depression, insomnia and anxiety than physicians. In another study from Singapore, nonmedical health care workers (allied health professionals, pharmacists, technicians, administrators, clerical staff and maintenance workers) had higher prevalence of anxiety than medical health care workers (physicians, nurses). This contrast may be attributed to the fact that India was in the early stages of this pandemic at the time of this study and nurses, owing to lesser medical knowledge about dangers of exposure than the doctors were less likely to be worried about dealing with COVID patients at that time.

Participants in our study were divided into two groups : i) those working in COVID health care facilities versus ii) those working in NON COVID health care facilities to compare differences in psychological impact between the two groups based on the risk of exposure The study revealed a higher prevalence of depression, generalized anxiety and panic symptoms among healthcare professionals working in COVID health care facilities compared to their counterparts working in NON COVID health care facilities in India. The findings from the present study are in congruence with the findings from previous studies on this pandemic from China. In the Chinese study frontline healthcare workers, and those working in Wuhan reported more severe degrees of symptoms than other health care workers. Our findings are however in contrast with another recent COVID-19 study demonstrating that frontline nurses had significantly lower vicarious traumatization scores than non-frontline nurses and the general public [6]. The findings of the study call for better psychological support and interventions as well as more intensive training on personal safety and infection control measures for healthcare workers working in COVID institutes. Proper supplies 
of personal protective equipment, adequate rest in between shifts and multi-disciplinary team approach can help to keep healthcare workers safe and in better mental health.

Multivariable logistic regression analysis also showed that, even after adjustment for confounders, females were more likely to be associated with depression and panic symptoms. Another finding from the analysis was doctors were more likely to suffer from depressive, obsessional and hypochondriacal symptoms. These findings suggest that special attention is required for mental health care in these two groups specially. The study had the limitation of having a cross sectional study design. With the study carried out during the initial phase of COVID pandemic in India, the possibility of underestimation of mental health problems cannot be completely denied. Because of the expected increase in the severity of the pandemic in India with time, studies with longitudinal follow ups are recommended to better assess the magnitude of the problem.

\section{CONCLUSIONS}

The study concludes that being a female health care professional, doctors and those working in COVID health care facilities were at a higher risk of having poor psychological health. Regular screening of these at-risk health care professionals should be done for early detection of psychological morbidities in them and immediate psychological interventions to address their mental health issues should be undertaken

\section{REFERENCES}

1. Wu Z, McGoogan JM. Characteristics of and important lessons from the coronavirus disease 2019 (COVID19) outbreak in China: summary of a report of 72314 cases from the Chinese Center for disease control and prevention. JAMA 2020;323(13):1239-42.

2. World Health Organization, 2020. WHO Director-General's opening remarks at the media briefing on COVID-19 - 11 March 2020. Retrieved from. https://www.who.int/dg/speeches/detail/who-directorgeneral-s-opening-remarks-at-the-media-briefing-on-covid-19---11-march-2020

3. World Health Organization, 2020. WHO coronavirus disease (Covid-19) dashboard. Retrieved from. https://covid19. who.int/?gclid=CjwKCAjwztL2BRATEiwAvnALcs3jNnqz2PXGXZXmFVKjeliybubcgGOsn6MgIm1s01iEEWVZbGGQRoCkGkQAvD_BwE

4. Ministry of Health and family welfare, 2020. Covid-19 India. Retrieved from. https://www.mohfw.gov.in/.

5. Lai J, Ma S, Wang Y, Cai Z, Hu J, Wei N, Wu J, et al. Factors associated with mental health outcomes among health care workers exposed to coronavirus disease 2019. JAMA Netw Open 2019;3(3):e203976e203976.

6. Li Z, Ge J, Yang M, Feng J, Qiao M, Jiang R, Bi J, Zhan G, Xu X, Wang L, Zhou Q. Vicarious traumatization in the general public, members, and non-members of medical teams aiding in COVID-19 control. Brain Behav Immun 2020;88:916-9.

7. Tan BY, Chew NW, Lee GK, Jing M, Goh Y, Yeo LL, Zhang K, Chin HK, Ahmad A, Khan FA, Shanmugam GN. Psychological impact of the COVID-19 pandemic on health care workers in Singapore. Ann Intern Med 2020;173(4):317-20.

8. Galea S, Merchant RM, Lurie N. The mental health consequences of COVID-19 and physical distancing: the need for prevention and early intervention. JAMA Intern Med 2020;180(6):817-8.

9. Kisely S, Warren N, McMahon L, Dalais C, Henry I, Siskind, D. Occurrence, prevention, and management of the psychological effects of emerging virus outbreaks on healthcare workers: rapid review and meta-analysis. Br Med J 2020;369.

10. World Health Organization, 1992. Clinical descriptions and diagnostic guidelines. The ICD-10 Classification of Mental and Behavioural Disorders.

11. News National. PM Modi announces 21-day lockdown as COVID-19 toll touches 12. The Hindu 2020. Retrieved from. https://www.thehindu.com/news/national/pm-announces-21-day-lockdown-as-covid-19toll-touches-10/article31156691.ece

12. Chahal S, Govil N, Gupta N, Nadda A, Srivastava P, Gupta S et al. Stress, coping and attitudinal change towards medical profession during COVID-19 pandemic among health care professionals in India: a cross sectional study. Indian Journal of Mental Health 2020;7(3):255-62.

$* * * * * * * * * * * * * * * * * * * * * * * * * * * * * * * * * * * *$

Acknowledgements - Nil; Funding - Nil, Conflict of Interest - Nil

Indian Journal of Mental Health 2021;8(4) 